

\title{
The Relation between the Type of Previous Delivery and Sexual Satisfaction in Women
}

\section{Poorandokht Afshari $^{1^{*}}$ and Zahra Salehnejad ${ }^{2}$}

${ }^{1}$ Reproductive Health Promotion Research Center, Ahvaz Jundishapur University of Medical Sciences, Ahvaz, Iran

${ }^{2}$ Ahvaz Jundishapur University of Medical Sciences arvand branch, Abadan, Iran

*Corresponding author

KEYWORDS

The type of delivery, Sexual satisfaction in women

The type of article: cross-sectional

\section{A B S T R A C T}

One of the reasons of uncontrolled increasing the elective cesarean in recent years, is the concerns about sexual activity and sexual disorders after a vaginal delivery. This study aimed to investigate the relationship between the type of previous delivery and sexual satisfaction in women referring to Shahid Mostafa Khomeini hospital in Behbahan. This cross-sectional study was performed on 277 married women aged 18-45 using simple random sampling referring to Shahid Mostafa Khomeini hospital in Behbahan from April to December in 2015. To collect data, a two part questionnaire including 14 questions of demographic characteristics and Larson sexual satisfaction questionnaire including 25 questionnaires was used. Data was analyzed with SPSS version 17, using analysis of variance ANOVA and more precise Test-Tukey test with a significance level of less than 0.05 . The amount of sexual satisfaction was higher in the people without delivery than in the persons with cesarean or vaginal delivery $(\mathrm{P}=0.001)$. The amount of sexual satisfaction was the same in the group of vaginal delivery and cesarean and no significant difference was there. The amount of sexual satisfaction in persons with 4 or more deliveries was lower than this amount in persons with one, two or three deliveries. The amount of sexual satisfaction was the same in the persons with one, two or three deliveries and no significant difference was there. The pregnancy process and delivery without concerning the type of delivery (the type of delivery does not affect the sexual satisfaction) affect the sexual relationship. This issue can be caused by interference of two roles of being mother and wife.

\section{Introduction}

Delivery is an issue that always women think about it. This issue has an extra- ordinary effect on mothers' mental and social health and their families (1). Delivery 
is a completely natural process which needs predictive and supportive measures not a pathological status which needs interference and cure (2). Vaginal delivery is the best option in most cases. After a vaginal delivery, women come back to the normal life faster, they have a better performance in different areas of health and different dimensions of quality of life than those women who have had cesarean, they are less affected by postpartum depression and they can establish better relationship with their family and their newborn (3).

One of the concerns of a society, especially the health officials of a country, is the increasing cesarean rate. It seems that the importance of women's selection and decision during their pregnancy has increased (4). In 2010, the rate of cesarean in Iran was announced 41.9 percent of all deliveries. And also, according to the health minister's report, the rate of cesarean in big cities is 55-60 percent and in the whole country is 44 percent which is a high number compared to its world rate (the rate of cesarean in the world is 20 percent). According to the statistics on the prevalence of cesarean, Iran after South America has the highest rate (2).

Spite of frequent recommendations of $\mathrm{WHO}^{1}$ about the cesarean rate, unfortunately it is increasing worldwide especially in developing countries. It is interesting that a significant proportion of elective cesarean is done at the request of the mother and her family and such a request has several causes including the creatingsexual disorder after a vaginal delivery. While such complaints and disorders is highly dependent on the beliefs and culture of a society (5).

One of the reasons of spouses' inclination toward cesarean is the effect of vaginal

\footnotetext{
${ }^{1}$ World Health Organization
}

delivery on the quality of sexual activity after delivery and women choose cesarean as a way to prevent perineal injury and sexual disorder after the delivery (4).

Statistics show that 5 percent of spouses experience sexual disorder in their marital life. 40 percent of spouses who are satisfied with their marital life are suffered from disorders in their sexual relationship or relative dissatisfaction with their sexual relations and about 5 percent of married women aged more than 35 never experience orgasm (6).

Barret et al. (2005) in this research on 796 women who had had their first delivery during 3 and 6 months after their childbirth (94 persons of them had cesarean section and the others had vaginal delivery), concluded that in spite of decreasing the sexual desire and increasing dyspareunia after vaginal delivery, there was no significant difference in sexual satisfaction between cesarean and vaginal delivery (7 and 2).

In a study conducted by Hantoushzadeh, it was announced that in the vaginal delivery group, the sexual satisfaction was significantly higher than it in the cesarean group (5). Bayttur et al. in a study entitled the effect of the delivery type on the strength of pelvic floor and sexual function after a delivery, concluded that there was no relation between muscles strength of the pelvic floor and sexual function in mothers and also between vaginal or cesarean sectionand sexual function (1).

Given the high rates of cesarean section in Iran and increased morbidity and mortality after that and also the positive attitude of women toward the effect of cesarean section in keeping the sexual function after delivery and conflicting studies related to the 
relationship between delivery type and sexual function, the researchers have attempted to study the effect of the delivery type and sexual function using documentary evidence.

\section{Procedure}

This research was a cross-sectional study conducted on 277 women in childbearing age referred to Shahid Mostafa Khomeini hospital in Behbahan from April to December in 2015, using simple random sampling. To collect the data, a two part questionnaire including 14 questions of demographic characteristics and Larson sexual satisfaction questionnaire including 25 questionnaires was used. Inclusion criteria included: being married,monogamous relationship, being 18-45 years old, and being literate. Exclusion criteria included: addiction to drug, alcohol, and cigarettes, consuming medicines which effect on the sexual relationship, infertility and lactation.Larson's sexual satisfaction questionnaire with 25 questions was used as an instrument to measure the sexual satisfaction. The data was analyzed in SPSS software version 17 using analysis of variance ANOVA and more precise TestTukey test with a significance level of less than 0.05 .

Findings: The research was conducted on 277 married women in childbearing age (1845). The average age of participants was 30.97. 72 persons of the participants did not have any child, 84 persons had 1 child, 29 persons had 3 and 25 persons had more than 3 children. 72 persons of them did not have the history of delivery and pregnancy. 106 persons of them had the history of vaginal delivery and 93 persons had the history of cesarean and 6 persons had the history of two types of deliveries. 31 persons were under diploma, 85 people were diploma and 161 persons were above diploma. 95 persons of the participants were employed and 18 people were unemployed. The average of age gap was 5.01 years. Among the subjects, the gap age in 174 persons was less than 5 years, in 80 persons was $6-10$, and in 23 persons was more than 10 years. Husbands of 30 the subjects of the participants were under diploma and husbands of 82 subjects were diploma and husbands of 165 subjects were above diploma.

Inthis research, first 277 married women, who were randomly selected, were divided into four groups?

Group 1: persons with the history of vaginal delivery; group 2: persons with the history of cesarean section; group 3: persons with the history of both types of delivery; group 4: persons without history of delivery. ANOVA test was used to compare the average of a variable in more than two independent groups and then to investigate more, Tukey Test was used. According to the findings, the percent of sexual satisfaction in women with the history of vaginal delivery was 73.85 (average: 92.31), in women with the history of cesarean section was 77.78 (average: 97.22), and in women with the history of both types of delivery was 76.93 (average: 96.16), and in women without the history of any delivery was 86.37 (average: 107.97). And also according to Table 2, the confidence level was 95 percent and the significance level of the variable was 0.05 so the amount of sexual satisfaction in the group 4 was higher than it in the group 3. $(\mathrm{p}=0.001)$ but the amount of satisfaction in the group 1 was the same with the group 2 and no significant difference was observed.

Another test was also conducted to investigate the sexual satisfaction in women 
with the history of delivery. Accordingly, the persons with the history of delivery were divided into four groups: group 1: persons with the history of one delivery; group 2: persons with the history of two deliveries; group 3: persons with the history of 3 deliveries and group 4: persons with the history of four or more deliveries. At first, the test was done using ANOVA method in the confidence level of 95 percent and the significance level of 0.017 . Based on the findings of this test, the average of sexual satisfaction among different groups had a significant difference. In other words, the number of previous deliveries had a significant effect on the sexual satisfaction so that the sexual satisfaction in women with the history of one delivery was $77.2 \%$ (average: 96.50), in women with the history of two deliveries was $75.12 \%$ (average: 93.91), in women with the history of three deliveries was $80.05 \%$ (average 100.06) and in women with the history of four or more deliveries was $66.96 \%$ (average: 83.71 ).

To further investigate, Tukey Test was used.

According to Table 3 and this fact that the significance level was less than 0.05 , the amount of sexual satisfaction in the group of persons with four or more deliveries was lower than it in the group of people with one, two or three deliveries. The amount of satisfaction in the group of women with one or two or three deliveries was the same and no significant difference was observed.

\section{Results and Discussion}

According to the obtained findings of this research, the amount of satisfaction in the group of women with vaginal delivery was the same with the satisfaction in the group of women with cesarean section. This finding is similar with the finding of the research conducted by Barret in 2005. He, with this hypothesis that cesarean section increases the sexual satisfaction, designed a study and concluded that in a vaginal delivery, in spite of decreasing sexual satisfaction and dyspareunia, the difference was not significant (5). And also, Goli et al. (20092010) conducted a study to investigate the function and sexual satisfaction in 180 women (90 women with the history of vaginal delivery and 90 women with cesarean section) with the history of vaginal delivery and cesarean section. Based on their findings, the sexual satisfaction and function in women who had had cesarean in the first three months after delivery was less, but after six months after the delivery, sexual satisfaction and function had no significant difference in both groups of cesarean section and vaginal delivery. This perhaps is due to this issue that in women with cesarean section, sexual activity in the first three months starts sooner (8). The research performed by Nikpoor and colleagues (2005-2006) about investigating the problems of sexual relations caused by delivery in women with the history of one delivery, also showed that there was no statistical relation between sexual problems, except anal intercourse $(\mathrm{p}<0.05)$, after delivery and the type of delivery (10).

However the study performed by Leadon Rochaly et al. to investigate the relationship between the type of delivery and public health in women who had their first deliveryduring 7 weeks after delivery, showed that public health in women who had had vaginal delivery was better than it in women who had had cesarean (2). Hantoushzadeh and colleagues in the research performed to compare sexual satisfaction of sexual relations after vaginal and elective delivery also showed that the sexual satisfaction in people with the history of vaginal delivery was significantly more than it in persons with the history of 
cesarean section (5). And also Griffths et al. in a study titled sexual function and morbidity of genitalia system after vaginal delivery and cesarean section, reported that sexual satisfaction in women after a vaginal delivery was less than it in women after a cesarean section and the prevalence of urinary incontinence, depression and dyspareunia after a vaginal delivery was more than them in a cesarean section (1). These findings do not confirm the findings of our research.

Also, based on the findings of our research, women who had not experienced a pregnancy and a delivery had more sexual satisfaction than those with the history of a delivery. And according to the significance level of less than 0.05 , the amount of sexual satisfaction in the group of thepersons without history of delivery was higher than it in persons with the history of cesarean and vaginal delivery.

This finding is similar to the findings of the studies which reported decreasing sexual desire after a delivery in women who had experienced their first delivery.

This study showed decreasing the sexual desire and satisfaction in people with the history of a delivery. Moreover, according to the findings of our research, the history of one to three deliveries did not cause any significant difference in women's sexual satisfaction, but after more than four deliveries, a significant difference was created in the sexual satisfaction of those women than it in women without the history of any delivery or those with the history of one to three deliveries. Other similar researches also confirm our findings. This research is consistent with the study of Poorakbaran and colleagues (2013-2014) about investigating the sexual function and satisfaction in women with or without the history of delivery. Based on their findings, a significant relation was obtained between sexual satisfaction and the amount of marital satisfaction. And also there was a significant relation between the marital satisfaction in women with the history of one delivery and women without any children so that the average score of sexual satisfaction of women with children was 3.4 and the score of women without children was 3.6 (6). So the marital satisfaction in women without a child was higher than it in women with children so that sexual factor played an important role in this issue. But other possible reasons such aseconomic problems after the birth, conflicts resulted of mother employment and having children, spending energy to take care of children, lack of opportunity and a suitable environment to have sexual relations with their spouses in families with many children, which all lead to lack of investment in relation with their husband,may play role in decreasing sexual satisfaction in women which can be studied in next studies. All the factors mentioned above create mental pressure which may lead to disorder in marital relations and decreasing sexual satisfaction.

The major limitation of our research was our failure to investigate sexual satisfaction before pregnancy and delivery in the subjects. However investigations performed by Byrd et al. (11) also prove our findings. In other word, despite of this belief that pelvic floor muscles relaxation after a vaginal delivery changes the sexual function and satisfaction in spouses, this is not true. It should be considered that to describe women's sexual response, emphasizing the responses of the genital tract and ways to satisfy sexual desire lead to neglect of more effective factors on women's sexual satisfaction such as intimacy, honesty, relaxation, relation, respect, emotions and satisfaction resulted from intimacy (8). 
Int.J.Curr.Res.Aca.Rev.2016; 4(2): 63-70

Table.1 Comparing the Demographic Characteristics and Background Variables of the Subjects

\begin{tabular}{|c|c|c|c|}
\hline variable & Indexes & frequency & average \\
\hline \multirow[t]{5}{*}{ age } & $18-25$ & 57 & 20.57 \\
\hline & $26-30$ & 86 & 31.04 \\
\hline & $31-35$ & 58 & 20.93 \\
\hline & $36-40$ & 49 & 17.68 \\
\hline & $41-45$ & 27 & 9.47 \\
\hline \multirow[t]{3}{*}{ education } & Under diploma & 31 & 11.19 \\
\hline & Diploma & 85 & 30.68 \\
\hline & Above diploma & 161 & 58.12 \\
\hline \multirow[t]{2}{*}{ occupation } & Employed & 95 & 34.29 \\
\hline & Unemployed & 182 & 65.70 \\
\hline \multirow{3}{*}{$\begin{array}{c}\text { Gap age } \\
\text { between spouses }\end{array}$} & Less than 5 years & 174 & 62.81 \\
\hline & $6-10$ years & 80 & 28.88 \\
\hline & More than 10 years & 23 & 8.30 \\
\hline \multirow[t]{3}{*}{$\begin{array}{c}\text { Education level } \\
\text { of the spouse }\end{array}$} & Under diploma & 30 & 10.3 \\
\hline & Diploma & 82 & 29.60 \\
\hline & Above diploma & 165 & 59.58 \\
\hline
\end{tabular}

Table.2 Tukey Test

\begin{tabular}{|c|c|c|c|c|c|c|}
\hline \multirow{2}{*}{$\begin{array}{l}\text { (I) } \\
\text { Deliver } \\
\mathrm{y}\end{array}$} & \multirow{2}{*}{$\begin{array}{c}\text { (J) } \\
\text { Delivery }\end{array}$} & \multirow{2}{*}{$\begin{array}{l}\text { The mean difference of } \\
\text { sexual satisfaction of } \\
\text { groups (I-J) }\end{array}$} & \multirow[t]{2}{*}{ Standard deviation } & \multirow{2}{*}{$\begin{array}{l}\mathrm{P}- \\
\text { value }\end{array}$} & \multicolumn{2}{|c|}{ Confidence interval of 95} \\
\hline & & & & & $\begin{array}{l}\text { Lower boun } \\
\text { bound }\end{array}$ & upper \\
\hline \multirow[t]{3}{*}{ vaginal } & cesarean & -4.91050 & 2.76635 & 0.288 & -12.0613 & 2.2403 \\
\hline & $\begin{array}{l}\text { Both } \\
\text { kinds of } \\
\text { delivery }\end{array}$ & -3.84891 & 8.16277 & 0.965 & -24.9491 & 17.2512 \\
\hline & $\begin{array}{l}\text { Without } \\
\text { history of } \\
\text { delivery }\end{array}$ & -15.65447 & 2.96575 & 0.001 & -23.3207 & -7.9882 \\
\hline \multirow[t]{2}{*}{ cesarean } & $\begin{array}{l}\text { Both } \\
\text { kinds of } \\
\text { delivery }\end{array}$ & 1.06159 & 8.19803 & 0.999 & -20.1297 & 22.2529 \\
\hline & $\begin{array}{l}\text { Without } \\
\text { history of } \\
\text { delivery }\end{array}$ & -10.74396 & 3.06145 & 0.003 & -18.6576 & -2.8303 \\
\hline $\begin{array}{l}\text { Both } \\
\text { kinds of } \\
\text { delivery }\end{array}$ & $\begin{array}{l}\text { Without } \\
\text { history of } \\
\text { delivery }\end{array}$ & -11.80556 & 8.26745 & 0.483 & -33.1763 & 9.5652 \\
\hline
\end{tabular}


Int.J.Curr.Res.Aca.Rev.2016; 4(2): 63-70

Table.3 Tukey Test

\begin{tabular}{|c|c|c|c|c|c|c|}
\hline \multirow{2}{*}{$\begin{array}{c}\text { The number } \\
\text { of deliveries } \\
\text { (I) }\end{array}$} & \multirow{2}{*}{$\begin{array}{l}\text { The number of } \\
\text { the previous } \\
\text { deliveries }(\mathrm{J})\end{array}$} & \multirow{2}{*}{$\begin{array}{c}\text { The mean } \\
\text { difference of } \\
\text { sexual satisfaction } \\
\text { of groups (I-J) }\end{array}$} & \multirow{2}{*}{$\begin{array}{l}\text { Standard } \\
\text { deviation }\end{array}$} & \multirow{2}{*}{$\begin{array}{c}\text { Significance } \\
\text { level }\end{array}$} & \multicolumn{2}{|c|}{ Confidence interval of 95} \\
\hline & & & & & Lower oud & pper overt \\
\hline \multirow[t]{3}{*}{1} & 2 & 2.59091 & 3.26566 & 0.428 & -3.8483 & 9.0301 \\
\hline & 3 & -3.560897 & 4.28520 & 0.406 & -12.0184 & 4.8805 \\
\hline & 4 & 12.78000 & 4.53433 & 0.005 & 3.8393 & 21.7207 \\
\hline \multirow[t]{2}{*}{2} & 3 & -6.15987 & 4.44592 & 0.167 & -14.9262 & 2.6065 \\
\hline & 4 & 10.18909 & 4.68651 & 0.031 & 0.9483 & 19.4298 \\
\hline 3 & 4 & 16.34897 & 5.44626 & 0.003 & 5.6101 & 27.0878 \\
\hline
\end{tabular}

Despite of this fact that many women select cesarean section due to lack of disturbance in a successful sexual relationship after a delivery, such a result was not found in investigations performed by many researchers. In other words, requests for a selective cesarean with the excuse of sexual satisfaction after delivery is not justified. Therefore according to the performed studies and the findings of this research, it seems that providing enough information about marital relations and premarital counseling can modify beliefs and attitudes of family members and impede their inclination toward cesarean section. Based on this finding that there was no significant difference in the sexual satisfaction in people with the history of one to three deliveries,contraception in order to prevention of disorders in sexual relations after delivery by women with a few children is not justifiable.

\section{References}

1. Afshari poorandokht, Malchi f,The effect of mode of delivery on postpartum sexual functioning in primiparous women[dissertation]. (Ahwaz, Iran): College of Nursing \&Midwifery, Ahvaz Jondishapour University of medical science;2006. (111).
2. Afshari poorandokht, Dabaghzadeh F, A comparative of pelvic floor muscle strength in vaginl delivery and caesarean section[dissertation]. (Ahwaz, Iran): College of Nursing \& Midwifery ,Ahvaz Jondishapour University of medical science and Faculty of arvand International Division; February 2013.(128).

3. Lydon-Rochelle MT, Holt VL, Martin DP.Delivery method and self-reported postpartum general health status among primiparous women.Pediater Perint Epidemiol 2001;15(3):232-40

4. Hehdari M, Merghati khoei E,Valaei N, The Effect of Mode of Delivery on Postpartum Sexual Functioning in Primiparous Women, Journal of Shahid Beheshti School of Nursing \& Midwifery 2010;20(68):20,21

5. Hantoushzadeh S, Shariat M,Rahimi Foroushani A, Ramezanzadeh F, Masoumi M. Sexual satisfaction after child birth: vaginal versus elective cesarean, delivery Tehran University Medical Journal March 2009 ; 66(12): 931

6. Poorakbaran E, Yaz A, The Study ofsexual function and marriage satisfaction in womenwith andwithoutdelivery past, Journal of Fundamentals of Mental Health 2015 July-Aug;67(4):203 
7. Connolly A, Throp J, Pahel L, Effect of pregnancy and childbirth on postpartum sexual function a longitudinal prospective study, J Int urogenital pelvic dysfunction Jul- Aug 2005

8. Ozgoli G, Dolatian M, Sheykhan Z, Valaei N. Study of sexual function and satisfaction in women with vaginal delivery and cesarean referring to Health Center of Shahid Beheshti Medical University-2008. Pejouhandeh 2011; 15(4): 258

9. Shams Mofaraheh Z ,Shahsiah M,Mohebi S,Tabaraee Y.The effect of marital counseling on sexual satisfaction of couples in Shiraz city. Health system research Journal 1389 autumn; 6(3):417424

10. Nikpour S, Javaheri I,Yadavar Nikravesh M, Jamshidi R.Study of sexual problems resulting from delivery in primiparous woman result to outpatient clinics in Wet of Tehran, Journal Iran university of medical. 2006;13(50):194.

11. Byrd JE, Hyde JS, DeLamater JD, Plant EA. Sexuality during pregnancy and the year postpartum. J Fam Pract1998;47(4):305-8.

\section{How to cite this article:}

Poorandokht Afshari and Zahra Salehnejad. 2016. The Relation between the Type of Previous Delivery and Sexual Satisfaction in Women. Int.J.Curr.Res.Aca.Rev. 4(2): 63-70. doi: http://dx.doi.org/10.20546/ijcrar.2016.402.007 